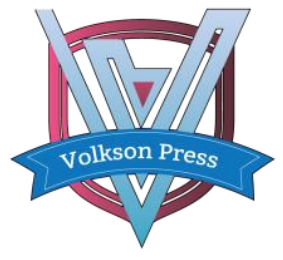

Economics, Finance and Statistics (EFS)

DOI : http://doi.org/10.26480/icefs.01.2018.85.86

\title{
THE IMPLICATIONS OF PHARMACEUTICAL ENGLISH CORPUS IN TEACHING
}

\author{
Haiqing Liu, Fahui Zeng, Longhuo $\mathrm{Wu}^{*}$ \\ Gannan Medical University, Ganzhou, Jiangxi, 341000, China \\ *Corresponding Author Email: longhwu@hotmail.com
}

This is an open access article distributed under the Creative Commons Attribution License, which permits unrestricted use, distribution, and reproduction in any medium, provided the original work is properly cited.

\section{ARTICLE DETAILS}

\section{Article History:}

Received 12 March 2018 Accepted 12 April 2018 Available online 15 May 2018

\section{ABSTRACT}

With the development of computer technology and internet, construction and research of corpus have made dramatic achievement, which brings positive challenges for language teaching. In our study, we introduced the construction of pharmaceutical English corpus and its implications in teaching. This is a new teaching idea and teaching method, stimulating the initiative of students to study professional English.

\section{KEYWORDS}

Corpus, pharmaceutical English, text, index line, collocation, thesaurus .

\section{INTRODUCTION}

Corpus is a collection according to a certain sampling standard, representing of an electronic text of a language or language variant. Corpus provides a large number of authentic language materials, which truly indicate the usage of language [1]. Study of corpus linguistics involved in teaching process in China dates back to the late or the beginning of the $20^{\text {th }}$ century. To date, various English corpuses deriving from teaching and in turn servicing for teaching have been established. The increasing development of corpus and its searching skills provides the valid and quantified information for teaching and research of English for specific purpose (ESP), which is an English class designed for some specific

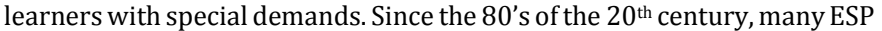
corpuses, such as scientific English corpus by Shanghai Jiaotong University and army English corpus by PLA Foreign Languages Institute, have been developed in China [2]. However, the research on pharmaceutical English corpus is still on the horizon. In this article, we will develop a small pharmaceutical English corpus for primary research its implications in teaching.

\section{CONSTRUCTION OF PHARMACEUTICAL ENGLISH CORPUS}

\subsection{Collection of texts}

To establish an effective corpus, validation of samples and balance between different subjects are the two major principles. Collecting and screening the samples randomly from the authoritative publishers or websites are of importance for suitable texts, which should be tagged with detailed elucidation. The origin of samples from different subjects is designed according to the standard of Chinese educational category and Chinese Pharmacopeia, which is divided into 4 first class subjects and 16 secondary class subjects (Table 1). To add new or some uncertain subjects, we design other secondary class subjects under each first class subjects. The ratios among the subjects are set by the situations of different subjects in the authoritative database and their ratio of subject arrangement in the universities. The category of samples includes published articles, dissertations, textbooks, and some popular science books. For the periodical, impact factors of scientific citation index in medicine, database of medicine, latest pharmaceutical information, and validation of origin are considered the influencing elements.

Table 1: The category of different subjects

\begin{tabular}{|c|c|c|}
\hline First class subjects & Ratio & Secondary class subjects \\
\hline Pharmacy (chemical drugs) & 50 & $\begin{array}{l}\text { Medicinal Chemistry, Pharmaceutical Preparations, Pharmaceutical analysis, Pharmacology, Clinical } \\
\text { Pharmaceutics, Toxicology, other pharmaceutics-related subjects }\end{array}$ \\
\hline Traditional Chinese Medicine & 20 & $\begin{array}{l}\text { Chinese Medicine Chemistry, Chinese Medicine Pharmacology, Identification of Chinese Materia Medica, } \\
\text { Chinese Medicine Processing, Pharmaceutics of Chinese Materia Medica, other Chinese Medicine-related } \\
\text { subjects }\end{array}$ \\
\hline Bioph & 22 & Natural Biological Drug, Biotechnology Drug, other biotechnology-related subjects \\
\hline Pharmacy Administration & 8 & $\begin{array}{l}\text { Drug Production Management and Quality Control, Drug Supervision and Adminis } \\
\text { Pharmacoeconomics, other pharmacy administration-related subjects }\end{array}$ \\
\hline
\end{tabular}

\subsection{Input of texts}

Integrity is under the critical consideration when the texts are input. The important elements of the samples, including title, abstract, keywords, authors, affiliations, and references, are input by different categories. Some equations, symbols, and figures are saved in the gallery. Besides, accuracy should be paid attention to ensure the validation of texts. They are checked carefully by more than two different operators, keeping away from the errors.

\subsection{Logicality of corpus}

Logicality of corpus, including original data and the texts, is associated with the data structure, which is processed in the certain computers. The original data of CPE (corpus of pharmaceutical English) include the origin of text and the category of subjects. Combination of original data and a piece of text forms a record of language. 


\subsection{The physical structure of corpus}

The physical structure of corpus is the way of text and data storage logically. Online of Pharmaceutical English corpus can be read in a browser/server-based dependent manner. On the format style, CPE does not include the traditional text. Due to the massive equation, symbols, figures, and tables in the literatures, we design "string" as the style to input the database. If the symbols can be recognized by Microsoft Word, they can be input by the operators. Otherwise, they will be captured and saved in the gallery, ensuring the integrity of the full article and facilitating the ease of being read online.

\section{THE IMPLICATION OF CORPUS IN PHARMACEUTICAL ENGLISH TEACHING}

\subsection{Statistics of term frequency}

The most common use of corpus is analysis of lexicon, especially the statistical investigation of term frequency, which the marker of quantitative analysis of all languages. This indicates that data of term frequency is the basis of research on language structure and use [3]. During the professional teaching, high frequency of lexicon relating to professional fields should be met with learners. On the conventional class, there is not exactly data basis but the individual experience and feeling for predicting the importance of a single word. Consequently, it would be not validated for a language-native teacher with rich knowledge of language to use term frequency and collocation, not less than a teacher with a secondary language [4].

After the establishment of a corpus, the list of term frequency in pharmaceutical English can be easily used. There are two parameters, including the frequency and the sequence, for a single word in the lexicon list. More often than not, a word listed in the front with higher frequency is of importance during the teaching course. Observations of a pharmaceutical English corpus developed by us indicate that the words in the top ten are function words, such as articles, prepositions, and conjunctions. This is consistent with those lexicons with high frequency in universal corpuses, such as BNC, BROWN. However, these function words are generally used for expressing grammar, not for the lexicon characteristics in a specific field. To develop a specific vocabulary for pharmaceutical English, these function words should be deleted. As a consequence, nouns with high frequency, such as drug, cell, metabolism, and apoptosis, come up to the top ten. This suggests that learners can capture the valuable information of research hotpot from such an observation in pharmaceutical English corpus.

\subsection{Analysis of index line}

There are many examples of language use in the corpus. Analysis of index line reveals that language characteristics and law hidden in the examples are the critical application of corpus in language teaching. The function of search in corpus is to output the index line, which demonstrates the search term and its language environment. This facilitates a learner to analyze the law of a language. Once a word was searched on the screen, the professor can easily take advantage of these to discuss with students, promoting their innovation.

\subsection{Analysis of collocation}

Collocation determines the capability of a language learner in producing texts, which is generally considered as key points and difficulties in learning languages. There is a large body of professional lexicons, as well as many common lexicons, in pharmaceutical English. However, these common lexicons express different meanings from those in universal English. For example, the word 'labor' means to work in universal English, while it means to bear a baby in pharmaceutical English. After analyzing the index line and the language environment of a professional word, a language learner can easily understand these complicated collocations. Similarly, a universal word in the professional article containing different information can be deduced quickly. Thus, the stylistic features of pharmaceutical English are implicated in these professional articles, meeting with a language learner.

\subsection{Thesaurus}

As mentioned above, analysis of term frequency, index line, and collocation is developed for a word searched in the phrase or sentence. However, it can't demonstrate the lexical relation in the continuing article. To find out the lexical features of a specific text or issue, the thesaurus, known as a word appears in the article at a super high frequency, should be clearly identified. Clear elucidation of the thesaurus is necessary to understand the relation between the distribution of lexicon and the main idea of article [5]. Observation corpus and reference corpus are the two key factors to be involved in generation of a thesaurus. Usually, the total amount of reference corpus is far more than that of observation corpus. Scientific English corpus JDEST, one of reference corpus, contains about 1 million terms. In our study, we have developed a pharmaceutical English corpus as an observation corpus, containing about 100 thousand terms. Thesaurus has been considered as a direction of research hotpots in professional fields. For example, the $\beta$ receptor blocker carvedilol, a thesaurus, is used for management of heart failure. This indicates that the rising trend of heart diseases incidence, which has attracted the attention of scientists.

\section{DISCUSSION}

Education of English language in Chinese medical university pays more attention to Basic English and neglects professional English. Students in medical university merely receive a two-year Basic English class, which results in difficulty with understanding professional foreign literatures and expressing their scientific ideas. Although professional English class has been designed in many medical universities, the teaching situation is far from satisfaction, due to the challenge of transformation from Basic English to professional English [6]. In addition, ESP has been implicated in conventional teaching model, while the ability of mastering professional English by students is still at the starting line. Here, we provided a new teaching idea and teaching method with development of pharmaceutical English corpus. With help of advanced technologies, the virtual language learning environment is provided by the corpus database, which triggers the initiative of students to study professional English.

\section{ACKNOWLEDGMENTS}

This study was financially supported by Educational Reform Project of Jiangxi Province (JXJG-13-13-3 and JXJG-14-13-10).

\section{REFERENCE}

[1] Liang, M.C., Li, W.Z., Xu, J.J. 2010. The application tutorial of corpus. Foreign language teaching and research press, Beijing.

[2] Lu, L., Zhang, G.Z. 2010. The construction and application of pharmaceutical English corpus. Today Pharmacy, 20(11), 63-66.

[3] Wang, M., Li, L.X. 2014. Construction and Application of Animal Science Research Articles Corpus. Journal of Anhui Agricultural Science, 42(20), 6854-6856.

[4] Fang, C.Y., Chen, X.L. 1992. The application of corpus in frequency count. Modern Foreign Language, 3, 43-51.

[5] Li, W.Z., Pu, J.Z. 2001. The use of concordance in EFL teaching. Journal of PLA University of Foreign Language, 24(2), 20-25.

[6] Wang, N. 2015. Construction of corpus-based vocabulary teaching model of Pharmaceutical English from the perspective of ESP. The Science Education Article Collects, 331, 169-170. 